\title{
Derechos humanos y manifestaciones públicas en Chile durante 2011: la audiencia pública ante la Comisión Interamericana de Derechos Humanos
}

Este artículo se encuentra disponible para su descarga gratuita en www.anuariocdh.uchile.cl

\section{Branislav Marelic Rokov}

Egresado de Derecho, Universidad de Chile. En 2011 presentó, junto a Ítalo Jaque, la audiencia "Derechos humanos y manifestaciones públicas en Chile" ante la $\mathrm{CIDH}$ en su $143^{\circ}$ período de sesiones, por el Programa Asesoría Ciudadana del Instituto Igualdad.

bmarelic@ug.uchile.cl

\section{RESUMEN}

Las multitudinarias manifestaciones públicas que se vivieron en Chile en 2011 generaron una violenta reacción por parte del Estado: se cercenó el derecho de reunión, se reprimió duramente a los manifestantes, y se cometieron incluso actos de tortura en contra de personas detenidas. Frente a esta situación, un grupo de estudiantes y abogados del Programa Asesoría Ciudadana del Instituto Igualdad decidió acudir a la Comisión Interamericana de Derechos Humanos para exponer estas violaciones de derechos humanos en una audiencia pública. Este artículo describe el contexto en el que se decidió acudir ante esta instancia internacional, el contenido de la denuncia ante la Comisión Interamericana, así como la respuesta del Estado y la reacción de la Comisión ante la exposición de estos hechos.

Palabras clave: Manifestaciones públicas - Derecho de reunión - Tortura - Violencia policial - Justicia militar

\section{SUMMARY}

The large scale public protests that took place in Chile in 2011 were met with violence on the part of the State: the right to freedom of assembly was curtailed, protesters were subjected to harsh repression and those detained were even tortured. In the face of this treatment, a group of students along with lawyers from the Citizens Advisory Program of Instituto Igualdad brought their case to the InterAmerican Commission on Human Rights so as to present these human rights violations in a public hearing. This article describes the context in which the decision was made to bring the matter before this international body, the content of the claim presented to the Inter-American Commission, as well as the State's answer and the Commission's reaction to the presentation of these facts.

Key words: Public protests - Freedom of assembly - Torture - Police brutality - Military jurisdiction

"[L]a participación política y social a través de la manifestación pública es importante para la consolidación de la vida democrática de las sociedades. Dicha participación, como ejercicio de la libertad de expresión y de la libertad de reunión, reviste un interés social imperativo, lo que deja al Estado un marco aún más ceñido para justificar una limitación de este derecho"

-Comisión Interamericana de Derechos Humanos, 2006

\section{Introducción: Las manifestaciones públicas en Chile durante 2011}

El año 2011 fue un año sin igual de movilizaciones por todo el mundo. Fue el año en que el manifestante -The Protester ${ }^{1}$ - se volcó a las calles a exigir mayor democracia y mayor equidad.

1 El Manifestante - The Protester- fue elegido por la Revista Time como Person of the Year 2011. La misma revista sostiene "In 2011, protesters didn't just voice their complaints; they changed the world". ANDERSEN, Kurt. "The 
Chile no fue la excepción, y durante siete meses se vivió una fuerte movilización ciudadana que se centró principalmente en exigir un sistema educacional de calidad y gratuito para todos. También hubo importantes movilizaciones ambientalistas y en apoyo a la causa mapuche.

Si hay algo que se puede destacar en Chile, además de la multitudinaria convocatoria, es que las demandas centrales del movimiento estudiantil no fueron meras demandas gremiales o exigencias sectoriales, sino que lo exigido encontró pleno reflejo en el desarrollo internacional del derecho a la educación. Así, los ciudadanos movilizados se convirtieron además en verdaderos defensores de derechos humanos.

Durante esos siete meses se manifestaron más de 2 millones de personas por todo Chile $^{2}$, existieron ocupaciones de recintos educacionales; hubo marchas, paros, cacerolazos, bloqueos del tránsito, intervenciones artísticas y activismo digital. Y durante este tiempo, numerosas organizaciones de la sociedad civil también se movilizaron en apoyo a los manifestantes ${ }^{3}$, revitalizando en gran medida el tejido social que estaba inmóvil desde la vuelta a la democracia. Sin embargo, con las movilizaciones también sobrevino una violenta respuesta del Estado de Chile. En reiteradas ocasiones la reacción hacia los ciudadanos fue brutal y el actuar de Carabineros recordó a muchos los 17 años de dictadura que se creían superados.

En el presente texto, quisiera contar la experiencia que me tocó vivir como parte de un excepcional grupo de personas ${ }^{4}$, que, reunidos en el Programa Asesoría Ciudadana del Instituto Igualdad, analizó e investigó la violencia policial ejercida sobre los manifestantes. Todos los hallazgos de aquel estudio fueron presentados en audiencia pública ante la Comisión Interamericana de Derechos Humanos (CIDH) en su $143^{\circ}$ período de sesiones, en octubre de $2011^{5}$. En este artículo presentaré entonces en primer lugar el contexto dentro del cual el Programa Asesoría Ciudadana decidió intervenir. En segundo lugar, se expone el contenido de la presentación que se realizó en la audiencia pública ante la $\mathrm{CIDH}$, para luego presentar la respuesta estatal y las reacciones de la CIDH frente a los hechos denunciados. Se finaliza con algunas conclusiones y perspectivas para el año 2012.

Protester". Time Person of the Year. 14 December 2011. [en línea] <http://www.time.com/time/specials/packages/ article/0,28804,2101745_2102132,00.html> [consulta: 15 marzo 2012].

2 Cifra entregada por el representante del Estado de Chile durante la audiencia pública "Derechos humanos y manifestaciones públicas en Chile", celebrada el 28 de octubre de 2011, $143^{\circ}$ período de sesiones de la Comisión Interamericana de Derechos Humanos.

3 Como el Centro de Estudios Jurídicos de la Federación de Estudiantes de la Universidad de Chile, la Comisión Ética contra la Tortura, o la Red de Abogados por la Defensa de los Derechos Estudiantiles (RADDE), entre muchas otras organizaciones. No debe dejar de mencionarse el invaluable trabajo del Instituto Nacional de Derechos Humanos en la observación de las manifestaciones y la intervención a favor de los detenidos.

4 En el equipo participaron, Juan Andrés Álvarez, Tania Busch, Héctor Valladares, Nicolás Facuse, Flavio Quezada, Ítalo Jaque, Carlos Navia, Danae Mlynarz, José Roa, Amaro Oróstica, Gustavo Namuncura, Ignacio Araya, Rafael Ferrada, Felipe Ferreira, Camila Garcés, Eduardo Chia, Francisco Gómez, Catalina Palma y Roberto Cárcamo. Además, se contó con la imprescindible ayuda de Danny Monsalvez, Marjorie Dinamarca, Manuel Campos, Juan Carlos Sharp, Constanza Medina, Fernando Pino, Javier Pineda, Octavio Morales, Pascual Cortés, Carolina Avilés, Natalia Flores, David Hernández Nava y Ernesto La Massa Brilhault. Para la preparación de la audiencia, además, usamos los valiosos consejos de Claudio Nash, Jorge Contesse y Macarena Sáez.

5 Audiencia pública "Derechos humanos y manifestaciones públicas en Chile", celebrada el 28 de octubre de 2011, $143^{\circ}$ período de sesiones de la Comisión Interamericana de Derechos Humanos (CIDH). El video de la audiencia está disponible en la página web de la CIDH. [en línea] <http://www.oas.org/OASPage/videosasf/2011/10/102811_4_S4.wmv> [consulta: 15 marzo 2012]. 


\section{La experiencia de la investigación en el contexto de las manifestaciones}

Cuando el movimiento comenzaba, por las mismas redes sociales que se usaron en la coordinación de movilizaciones, se empezaron a ventilar denuncias de torturas y agresiones de Carabineros, se difundieron fotografías y videos que evidenciaban hechos condenables. Por otra parte, nosotros mismos, cuando salimos a manifestarnos, empezamos a notar que el actuar policial en la disuasión de concentraciones era totalmente desproporcionado.

Ante esta situación, formulamos la siguiente hipótesis: existen patrones sistemáticos de violencia policial hacia los manifestantes. Esta hipótesis, para nada novedosa, había sido enunciada en 2008, por diversas organizaciones como Amnistía Internacional Chile, en el marco del programa “¡Alto Ahí! Basta de Violencia Policial”6.

Sin embargo, el gran desafío no era descubrir la hipótesis, sino probarla. ¿Cómo se puede probar que agentes del Estado abusaban sistemáticamente de manifestantes? La única forma que consideramos viable fue la recolección masiva de testimonios directos de víctimas y todo tipo de pruebas audiovisuales posibles.

El proceso de recolección de información se inició a fines de julio, a través de un sitio web y de visitas a establecimientos educacionales. Los primeros relatos, obtenidos en el Instituto Nacional -el establecimiento público de enseñanza media más antiguo del país-, se referían a amenazas de muerte proferidas por funcionarios policiales, tratos abusivos al interior de buses policiales y referencias racistas hacia un niño de ascendencia mapuche. A lo largo de nuestro trabajo nos encontramos también con relatos crudos, violentos e indignantes de niños, niñas y jóvenes amenazados por agentes del Estado, amenazas de desaparición forzada; conocimos víctimas de brutales golpizas, vejaciones e incluso intentos de violación. Por otra parte, durante ese tiempo en cada movilización vimos y sufrimos de la reacción generalmente desproporcionada e indiscriminada de la fuerza pública.

La escalada de violencia, tanto de la policía como de los manifestantes violentos -los encapuchados-, tuvo un hito el 4 de agosto de 2011. En esa ocasión, más de 1.000 efectivos de Carabineros disolvieron violentamente las marchas que se intentaron por el centro de Santiago ${ }^{7}$ y por diversas regiones del país. Durante esos días, la autoridad, lejos de cuestionar o revisar sus procedimientos en el control de manifestaciones, derechamente prohibió las marchas por la Alameda ${ }^{8}$-la principal avenida del centro de la capital- y calificó a las manifestaciones fuera del ordenamiento jurídico ${ }^{9}$ en base a una normativa de la dictadura militar, el Decreto Supremo No. 1.086 de 1983 (en adelante "DS 1.086") ${ }^{10}$.

6 "La campaña [...] sensibilizará a la opinión pública y denunciará el preocupante aumento de situaciones graves de violencia policial, que lesionan la vida, la integridad personal y la seguridad humana. Generará propuestas de modificación a los mecanismos que permiten la violencia policial y promoverá las garantías de la ciudadanía en el marco de los Derechos Humanos internacionalmente reconocidos y la paz social.” Ver: “¡AAlto ahí! Basta de Violencia Policial', la nueva campaña contra la represión brutal". El Ciudadano. 10 de septiembre de 2008. [en línea] <http:// www.elciudadano.cl/2008/09/10/2949/alto-ahi-\%E2\%80\%93-basta-de-violencia-policial/> [consulta: 15 marzo 2012].

7 Ver: "Intendenta Metropolitana Ilama a no adherirse a una marcha fuera del marco legal". Radio Biobío. 4 de agosto de 2011. [en línea] <http://www.biobiochile.cl/2011/08/04/intendenta-metropolitana-llama-a-no-adherirse-a-una-marchafuera-del-marco-legal.shtml> [consulta: 15 marzo 2012].

8 Ver: "Hinzpeter: 'se acabaron las marchas estudiantiles por la Alameda'". La Nación. 3 de agosto de 2011. [en línea] $<$ http://www.lanacion.cl/hinzpeter-se-acabaron-las-marchas-estudiantiles-por-la-alameda/noticias/2011-08-03/122746. html> [consulta: 15 marzo 2012].

9 Ver: “Intendenta a padres por marchas: 'Sus hijos arriesgan salir lesionados'”. El Mercurio. 4 de agosto de 2011. [en línea] <http://www.emol.com/noticias/nacional/detalle/detallenoticias.asp?idnoticia=496105> [consulta: 15 marzo 2012].

10 Decreto Supremo No. 1.086 sobre Reuniones Públicas. Ministerio del Interior, República de Chile, 16 de septiembre de 1983. En adelante "Decreto Supremo No. 1.086". 
En este contexto, nos dimos cuenta de que el Estado no estaba entendiendo a cabalidad la forma correcta de lidiar con una ciudadanía empoderada y, lejos de proteger el derecho a reunión y libertad de expresión, lo estaba cercenando. Es por esto que se decidió acudir a organismos internacionales, en específico a la $\mathrm{CIDH}$, para allí argumentar que la reacción estatal era totalmente incomprensible en un Estado democrático ${ }^{11}$.

\section{La denuncia de los abusos en la audiencia pública ante la CIDH}

A continuación abordaré los principales aspectos de la presentación que se realizó ante la Comisión Interamericana en la audiencia pública de octubre de 2011, centrándome en primera instancia en el marco normativo sobre manifestaciones, para luego revisar prácticas de violencia identificadas en 2011, y finalizar con la explicación de una de las causas que permite que estas prácticas se repitan.

\subsection{El marco normativo sobre manifestaciones públicas en Chile}

La Constitución Chilena en su artículo 19 No. 13 establece: "El derecho a reunirse pacíficamente sin permiso previo y sin armas. Las reuniones en las plazas, calles y demás lugares de uso público, se regirán por las disposiciones generales de policía" ${ }^{12}$.

Si bien el primer inciso establece claramente la palabra sin permiso previo y sin armas, lo cierto es que la segunda parte del artículo remite al reglamento, la regulación concreta, esto es, al DS 1.086.

EI DS 1.086, dictado en plena dictadura militar, establece un sistema de autorización previa para toda reunión o manifestación pública, con requisitos bastante cuestionables en una sociedad democrática. Así, el artículo 2 b) del Decreto establece que "[e]l aviso indicado deberá ser por escrito y firmado por los organizadores de la reunión, con indicación de su domicilio, profesión y número de su cédula de identidad. Deberá expresar quiénes organizan dicha reunión, qué objeto tiene, dónde se iniciará, cuál será su recorrido, donde se hará uso de la palabra, qué oradores lo harán y dónde se disolverá la manifestación"13. Este régimen de autorización previa proscribe, en consecuencia, toda manifestación espontánea o manifestación sin una clara organización convocante. El no cumplimiento de las condiciones, o la no autorización, ocasionará la disolución inmediata de toda reunión por la fuerza pública, es decir, por Carabineros de Chile $^{14}$.

La ideología subyacente del DS 1.086 es que toda manifestación pública -marchas, cacerolazos, reuniones, etc.-, que afecte o no el libre tránsito, está supeditada a la aquiescencia del Gobierno. Esto constituye realmente una suerte de censura previa y una regulación inaceptable del derecho de las personas de ocupar el espacio público como espacio de participación política.

A nivel interamericano, la $\mathrm{CIDH}$ ha sostenido que "[l]a finalidad en la reglamentación del derecho de reunión no puede ser la de crear una base para que la reunión o la manifestación sea prohibida. Por el contrario, la reglamentación que establece, por ejemplo, el aviso o notificación previa, tiene por objeto informar a las autoridades para que tomen las medidas conducentes a facilitar el ejercicio del derecho sin entorpecer de manera significativa el desarrollo normal de

\footnotetext{
11 Para el momento de acudir a la Comisión contábamos con más de 140 testimonios de abusos y con cerca de 150 videos de violencia policial.

12 Constitución Política de la República de Chile de 1980, artículo 19 No. 13.

13 Artículo 2 letra b) del Decreto Supremo No. 1.086.

14 Artículo 2 letra e) del Decreto Supremo No. 1.086 establece: "Si llegare a realizarse alguna reunión que infrinja las anteriores disposiciones, podrá ser disuelta por las fuerzas de Fuerzas de Orden y Seguridad Públicas."
} 
las actividades del resto de la comunidad" y "[n]o se puede considerar el derecho de reunión y manifestación como sinónimo de desorden público para restringirlo per se $\mathrm{e}^{\prime 15}$.

Así, si cotejamos el DS 1.086 con los estándares interamericanos y con el artículo 15 de la Convención Americana sobre Derechos Humanos $(\mathrm{CADH})^{16}$, podemos darnos cuenta que el Estado viola flagrantemente la $\mathrm{CADH}$, ya que la autorización previa es incompatible con un Estado democrático. Por otra parte, se debe destacar que el Decreto Supremo es en sí una violación a la $\mathrm{CADH}$, ya que regula por normas infralegales, algo que la Convención manda que se regule por ley -el derecho de reunión-. Incluso en el reciente Segundo Informe sobre la situación de las defensoras y defensores de derechos humanos de 2011, la Comisión ha cuestionado directamente el DS $1.086^{17}$.

\subsection{Las (viejas) prácticas de violencia policial}

\section{a. Intervención desproporcionada en manifestaciones}

Además del marco normativo adverso, pudimos identificar ciertos patrones del actuar policial totalmente reñidos con el uso legítimo de la fuerza. Estas prácticas fueron identificadas luego de la revisión de videos ${ }^{18}$ obtenidos del sitio Youtube, de Facebook o de manera directa. De esta forma nos encontramos con: violencia innecesaria ${ }^{19}$, golpes con bastones retráctiles ${ }^{20}$; uso excesivo de bombas lacrimógenas ${ }^{21}$ disparadas incluso al cuerpo de los manifestantes ${ }^{22}$; utilización de carros lanzagua sin mediar provocación o en lugares inexplicables ${ }^{23}$ y detenciones masivas o selectivas ${ }^{24}$. Se debe destacar que además de la violencia generalizada contra manifestantes, la prensa sufrió

$15 \mathrm{CIDH}$. Informe sobre la situación de las defensoras y defensores de los derechos humanos en las Américas. 7 de marzo de 2006. OEA/Ser.L/V/II.124, Doc. 5 rev.1., párrs. 56 y 60.

16 El artículo 15 establece: “Se reconoce el derecho de reunión pacífica y sin armas. El ejercicio de tal derecho sólo puede estar sujeto a las restricciones previstas por la ley, que sean necesarias en una sociedad democrática, en interés de la seguridad nacional, de la seguridad o del orden públicos, o para proteger la salud o la moral públicas o los derechos o libertades de los demás". OEA. Convención Americana sobre Derechos Humanos (CADH). Adoptada en noviembre de 1969. Ratificada por Chile el 5 de enero de 1991.

$17 \mathrm{CIDH}$. Segundo Informe sobre la situación de las defensoras y defensores de los derechos humanos en las Américas. 31 de diciembre 2011. OEA/Ser.L/V/II. Doc. 66 31, párr. 140.

18 Se analizaron más de 300 videos hasta el 6 de octubre de 2011.

19 Ver videos: "Represión Nacional V". [en línea] http://www.youtube.com/watch?v=feVCRMmbkes>; y "Carabinero golpea en la cara a estudiante en Linares ¿Era necesario? Juzge [sic] usted!" [en línea] <http://www.youtube.com/ watch?v=j829_Jb9RZo> [consulta: 15 marzo 2012].

20 El registro más claro fue tomado en la marchas del "Día de la Raza" en Santiago. Si bien no fue una marcha del movimiento estudiantil, si se enmarca en pleno período de movilizaciones. Ver: "Video muestra golpiza de carabinero a manifestante en el suelo tras marcha del Día de la Raza". Radio Biobío. 10 de octubre de 2011. [en línea] <http://www.biobiochile. cl/2011/10/10/video-muestra-golpiza-de-carabinero-a-manifestante-en-el-suelo-tras-marcha-del-dia-de-la-raza.shtml> [consulta: 15 marzo 2012].

21 Ver: "Video en donde se aprecia a Carabineros utilizando bombas lacrimógenas para disuadir un cacerolazo en un pasaje residencial: Reprimiendo el cacerolazo residencial" [en línea] <http://www.youtube.com/watch?v=u3rkrO1X6Ds> [consulta: 15 marzo 2012].

22 Ver: "Carabineros lanza bombas lacrimógenas a quemarropa". El Dínamo. 30 de agosto de 2011. [en línea] <http:// www.eldinamo.cl/tumblr/carabineros-lanza-bombas-lacrimogenas-a-quemarropa/> [consulta: 15 marzo 2012].

23 Ver los siguientes videos: "Abuso de Poder..." [en línea] <http://www.youtube.com/watch?v=kN-Sv6w2VB4>; y "FF. EE. contra Casa Central PUCV 30/06/2011". [en línea] <http://www.youtube.com/watch?v=K801zEbEiDs> [consulta: 15 marzo 2012].

24 De esto puedo dar cuenta personalmente, ya que el 4 de agosto de 2011 fui detenido sin motivo por Carabineros. No se me imputó cargo penal y luego de estar privado de libertad en un camión policial y en calabozo por cerca de 3 horas, fui liberado. En esa ocasión habían más de 20 personas en la misma situación, incluido Ítalo Jaque, expositor en la audiencia pública. 
numerosos ataques. Esto provocó que la organización Reporteros Sin Fronteras bajara a Chile 47 puestos en el ranking de libertad de prensa ${ }^{25}$. Más aún, la fuerza pública se ejerció indiscriminadamente, tanto sobre manifestantes pacíficos como sobre transgresores de la ley, evidenciando que Carabineros no tiene dentro de sus órdenes la protección de los manifestantes pacíficos, sino el despeje total de los espacios públicos, por todos los medios necesarios.

En este respecto, el Instituto Nacional de Derechos Humanos (INDH), en su Informe Anual publicado en diciembre de 2011, afirma que existieron detenciones arbitrarias ${ }^{26}$, que se usó indiscriminadamente el gas lacrimógeno y se disparó al cuerpo ${ }^{27}$, respaldando lo anteriormente descrito y expuesto en octubre en la audiencia pública.

Sobre este tema la CIDH ha sostenido que "el grado de fuerza ejercido por los funcionarios del Estado para que se considere adecuado con los parámetros internacionales, no debe ser más que el 'absolutamente necesario'. El Estado no debe utilizar la fuerza en forma desproporcionada ni desmedida contra individuos que encontrándose bajo su control, no representan una amenaza, en tal caso, el uso de la fuerza resulta desproporcionado" 28 .

Con lo anterior, no caben muchas dudas que en 2011, el Estado de Chile ejerció la fuerza de manera totalmente desproporcionada, indiscriminada y violando toda la normativa internacional sobre la materia.

\section{b. La tortura}

Durante el trabajo en 2011 se recibieron relatos escabrosos de manifestantes que, luego de ser detenidos, fueron castigados al interior de vehículos policiales y recintos policiales. El concepto de tortura ${ }^{29}$, definida en la Convención Interamericana de la materia, se aplica claramente a los casos $\operatorname{conocidos}^{30}$.

En la audiencia pública, Ítalo Jaque pudo leer dos testimonios representativos y exhibir fotografías del rostro de una de las víctimas con muestras evidentes de violencia. Las torturas generalmente se llevaron a cabo en el tiempo que mediaba entre la detención y el arribo a las comisarías. Los hechos de violencia en los recintos policiales son aislados, ya que fueron evitados en muchos casos por la sola presencia en calabozos de observadores del Instituto Nacional de Derechos

25 Reporters Without Borders. World Press Freedom Index 2011-2012. [en línea] <http://en.rsf.org/IMG/CLASSEMENT_2012/C_ GENERAL_ANG.pdf> [consulta: 15 marzo 2012].

26 Este informe indica que: "En efecto, el sistema de persecución criminal opera deteniendo preventiva, aleatoria y arbitrariamente, como una forma de controlar -ilegítimamente- las manifestaciones". Instituto Nacional de Derechos Humanos (INDH). Situación de los derechos humanos en Chile. Informe Anual 2011. Santiago: INDH, 2011, p. 77.

27 Ibídem, pp. 79 y ss.

$28 \mathrm{CIDH}$. Informe sobre la situación de las defensoras y defensores..., op. cit., párr. 65.

29 OEA. Convención Interamericana para Prevenir y Sancionar la Tortura. Adoptada el 12 de septiembre de 1985. Ratificada por Chile el 30 de septiembre de 1988. En su artículo 2 establece: "Para los efectos de la presente Convención se entenderá por tortura todo acto realizado intencionalmente por el cual se inflijan a una persona penas o sufrimientos físicos o mentales, con fines de investigación criminal, como medio intimidatorio, como castigo personal, como medida preventiva, como pena o con cualquier otro fin. Se entenderá también como tortura la aplicación sobre una persona de métodos tendientes a anular la personalidad de la víctima o a disminuir su capacidad física o mental, aunque no causen dolor físico o angustia psíquica".

30 "Denuncia Tortura tipo Guantánamo contra estudiante de 18 años". La Nación. 27 de octubre de 2011. [en línea] <http:// www.lanacion.cl/denuncian-tortura-tipo-guantanamo-contra-estudiante-de-18-anos/noticias/2011-10-27/190822.html>; y "Fui Torturado por Carabineros". La Nación. 29 de Agosto de 2011 [en línea] <http://www.lanacion.cl/universitarioacusa-fui-torturado-por-carabineros/noticias/2011-08-29/001405.html> [consulta: 15 marzo 2012]. 
Humanos. Estos funcionarios fueron Ilamados en una ocasión "pirañas de derechos humanos"31 por los mismos efectivos policiales.

Tanto los casos de tortura como los casos de detención ilegal o violencia desproporcionada que conocimos fueron denunciados ante la justicia ordinaria con la autorización de las víctimas. Se tiene conocimiento que otras organizaciones también han denunciado numerosos casos de violencia ${ }^{32}$.

\section{c. La herencia de las viejas prácticas}

¿Son los hechos antes descritos novedosos en Chile? Preocupantemente, no. Y esto se demuestra leyendo los mismos informes de la CIDH sobre Chile de los años 70 y $80^{33}$. A continuación se citan algunos pasajes seleccionados:

Durante el período que se considera, han sido numerosas las muertes imputables a agentes gubernamentales registradas por organismos defensores de los derechos humanos. Las modalidades asumidas por estas violaciones son diversas:

a. Las realizadas con motivo de la represión de las jornadas de protesta y de otras manifestaciones masivas constituyen el grupo mayoritario. Ellas han sido el resultado de los desproporcionados medios empleados por los organismos encargados del orden, los cuales han alcanzado en oportunidades a transeúntes o simples espectadores, como así también a personas que se encontraban dentro de sus residencias. [...]

En otras oportunidades las muertes han ocurrido como consecuencia del disparo de bombas de gases lacrimógenos dirigidos al cuerpo de los manifestantes, así como por efecto de balines defectuosos empleados para dispersar manifestaciones.

b. También se han producido muertes por abuso de poder de miembros de las fuerzas de seguridad, los cuales han actuado sin que exista motivación política alguna. Se trata de casos aislados pero que revelan un peligroso estado de descontrol de algunos miembros de esos organismos que podrían estar actuando a la sombra de la impunidad de que parecen gozar $[\ldots]$

Con respecto al derecho a la integridad física y la seguridad personal, deben considerarse dos tipos de situaciones. El primero se vincula de manera directa con actos de represión de las manifestaciones masivas y cubre los heridos ocurridos en esas circunstancias. El segundo se refiere a las reiteradas denuncias por torturas de personas mientras se encontraban detenidas $[\ldots]$

A lo expresado respecto al derecho de reunión debe sumarse la violencia desproporcionada empleada por las fuerzas de seguridad en la represión de manifestaciones, lo cual ha actuado también como disuasivo de participar en ellas. La situación mencionada se agrava por recientes declaraciones de las más altas autoridades gubernamentales que han manifestado su voluntad de actuar con la mayor energía ante futuras manifestaciones ${ }^{34}$.

31 Según testimonio de una víctima, cuando se aproximaban a la 3era Comisaría de Santiago, uno de los efectivos de Carabineros, al ver a personal del INDH dijo "Ya están las pirañas de derechos humanos, lo único que quieren es plata".

32 Por ejemplo la Corporación Humanas denunció un hecho de violencia sexual el 18 de enero de 2012. Ver: "Interponen querella por violencia sexual en contra de estudiante durante protesta en el río Mapocho". Radio Biobío. 18 de enero de 2012. [en línea] <http://www.biobiochile.cl/2012/01/18/interponen-querella-por-violencia-sexual-en-contra-deestudiante-durante-protesta-en-el-rio-mapocho.shtml> [consulta: 15 marzo 2012].

33 Especialmente ver CIDH. Informe Anual de la Comisión Interamericana de Derechos Humanos 1983-1984. Capítulo VI: "Situación de los derechos humanos en varios Estados: Chile". 28 de septiembre de 1984. OEA/Ser.L/V/II.63 doc. 10. [en línea] <http://www.cidh.oas.org/annualrep/83.84sp/cap.4a.htm> [consulta: 15 marzo 2012].

34 Ibídem, párrs. 12-20. Negritas agregadas. 
En Chile, tristemente, todavía existe una cultura de abusos muy arraigada en la institucionalidad policial y las mismas prácticas que se registraron en plena dictadura se reproducen hoy, en democracia.

\subsection{Causas de la persistencia de la violencia policial: impunidad y justicia militar}

¿Por qué se siguen produciendo estos actos de violencia? Existen varios factores que perpetuán la cultura de abusos, pero el principal sigue siendo la existencia de la justicia militar ${ }^{35}$, sistema judicial altamente cuestionado desde 2005 por la sentencia de la Corte Interamericana de Derechos Humanos en el caso Palamara Iribarne vs. Chile ${ }^{36}$.

La justicia militar chilena, como lo ha sostenido el Informe Anual de 2011 de la Universidad Diego Portales "más parece un privilegio que una judicatura especializada" 37 . Y en efecto, la justicia militar es una justicia que carece totalmente de imparcialidad ${ }^{38}$, con procedimientos violatorios de numerosas garantías judiciales ${ }^{39}$.

Si bien en 2011 se reformó en parte la justicia militar, sustrayendo a los civiles de la jurisdicción castrense, todavía falta otra reforma ${ }^{40}$ que restrinja el alcance de la jurisdicción a materias propias de la esfera militar. En ese sentido resulta claro el razonamiento de la Corte IDH: "si los actos delictivos cometidos por una persona que ostente la calidad de militar en activo no afectan los bienes jurídicos de la esfera castrense, dicha persona debe ser siempre juzgada por tribunales ordinarios. En este sentido, frente a situaciones que vulneren derechos humanos de civiles bajo ninguna circunstancia puede operar la jurisdicción militar" ${ }^{41}$.

Actualmente, la mayoría de los actos de tortura o de violencia en manifestaciones públicas, perpetrada por funcionarios policiales se dirige a tribunales militares y no a los juzgados ordinarios ${ }^{42}$. La sensación de libertad que genera entre los funcionarios este fuero de privilegio, permite sin lugar a dudas que muchos de los abusos continúen al amparo de la impunidad de la que parecen gozar.

35 La justicia militar resulta aplicable a Carabineros de Chile, por ser una institución de carácter militar según prescribe el artículo $6^{\circ}$ del Código de Justicia Militar de la República de Chile.

36 Corte IDH. Caso Palamara Iribarne vs. Chile. Fondo, Reparaciones y Costas. Sentencia de 22 de noviembre de 2005. Serie C No. 135.

37 Centro de Derechos Humanos, Universidad Diego Portales (UDP). Informe Anual sobre Derechos Humanos en Chile 2011. Santiago: Ediciones de la Universidad Diego Portales, 2011, p. 129.

38 Corte IDH. Caso Palamara Iribarne vs. Chile, op. cit., párr. 155.

39 Ibídem, párrs. 162 y ss.

40 El Código de Justicia Militar sigue estableciendo que un militar, por el hecho de ser militar debe ser juzgado por el fuero castrense. En palabras del informe anual de la Universidad Diego Portales "las tareas de reforma no han sido suficientes, porque el foco de aplicación sigue siendo la calidad del sujeto y no la afectación de bienes jurídicos propios del orden militar (como ordena la Corte Interamericana), lo que permite que se les juzgue por la comisión de delitos comunes, con lo que se afecta gravemente la igualdad ante la ley." Centro de Derechos Humanos UDP. Informe Anual sobre Derechos Humanos en Chile 2011, op. cit., p. 141.

41 Corte IDH. Caso Radilla Pacheco vs. México. Excepciones Preliminares, Fondo, Reparaciones y Costas. Sentencia de 23 de noviembre de 2009. Serie C No. 209, párr. 274.

42 Sin perjuicio de esto, existen casos en que los tribunales ordinarios se han declarado competentes como en una querella por tormentos interpuesta por el abogado Eduardo Chia. El juez Cristián Sánchez Rivera, en febrero de 2012, ante la solicitud de incompetencia de la Fiscalía, reafirmó su competencia sosteniendo que "las acciones [...] que cometieron los funcionarios policiales, en contexto de la denuncia materia de esta querella, no puede sostener este tribunal que se trata de actos propios del cargo de los funcionarios judiciales, por el solo hecho de que estos llevasen consigo eventualmente algún uniforme que los pudiese caracterizar, la sola circunstancia de obrar en ese contexto, esto es, amparado bajo el uniforme, no genera ni transforma los actos que ejecutan las policías en un estatuto que a todo evento importe sólo y siempre la infracción de tipos penales y de obligaciones que en definitiva van a ser de conocimiento exclusivamente de la Justicia Militar [...]". $7^{\circ}$ Juzgado de Garantía de Santiago. Causa RIT 16253-2011. Resolución de 17 de febrero de 2012. 


\section{La respuesta del Estado en la audiencia pública}

Luego de nuestra exposición en la audiencia, que abordó una estructura similar a la desarrollada en este artículo, el Estado de Chile contestó los cuestionamientos, a través del Director de Derechos Humanos del Ministerio de Relaciones Exteriores, Miguel Ángel González, y el Mayor de Carabineros de Chile, Heriberto Navarro.

El Estado comenzó su intervención afirmando que el principal problema es la violencia, y que de ninguna forma en Chile existe impedimento alguno para el ejercicio del derecho a la reunión o libertad de expresión. Es más, sostuvo que "cuando se dice o cuando se quiere insinuar que hay una oposición del Estado a que se manifiesten los ciudadanos, eso es una falsedad. No se requiere autorización, lo que se requiere es que se informe y se acuerde un recorrido para la marcha" ${ }^{43}$.

Luego, el Director de Derechos Humanos hizo hincapié y habló in extenso de la violencia protagonizada por encapuchados. El Estado afirma -correctamente- que se debe intervenir contra los manifestantes que se tornan violentos. En una segunda parte, el Mayor Navarro enfatiza que las Fuerzas Armadas son esencialmente obedientes y no deliberantes, y que su rol es el aseguramiento del orden público cuando éste es quebrantado, con apego a la normativa vigente. Afirma además que se están cursando investigaciones a los efectivos policiales que protagonizaron excesos.

En nuestra réplica, se insistió especialmente en dos puntos no tocados por la contestación estatal: la legitimidad del Decreto Supremo No. 1.086 y la reforma a la justicia militar. Además se hizo ver que el foco de la audiencia no era hablar de los encapuchados-objeto de una legítima persecución apegada a la proporcionalidad del uso de la fuerza-, sino de manifestantes pacíficos abusados y torturados por agentes del Estado.

En la dúplica, el Estado argumenta que el DS 1.086 es compatible con la CADH, ya que citado el párrafo 36 de la Opinión Consultiva No. 6 de la Corte IDH, el decreto cabría dentro del concepto de ley manejado por la Convención. Con respecto a la jurisdicción militar, el Estado informa que se está trabajando en nuevos proyectos de ley y pide paciencia, pues "Ios cambios culturales no se dan de un día para otro" ${ }^{44}$.

Frente a esta defensa del Estado, es posible responder que la doctrina de Cancillería que asimila el DS 1.086 a una ley, está rotundamente equivocada. La Corte IDH, en la misma Opinión Consultiva No. 6 a la que hizo referencia el Estado estimó que "no es posible interpretar la expresión leyes, utilizada en el artículo 30, como sinónimo de cualquier norma jurídica", por lo tanto, "las leyes a que se refiere el artículo 30 son actos normativos enderezados al bien común, emanados del Poder Legislativo democráticamente elegido y promulgados por el Poder Ejecutivo" ${ }^{\prime 5}$.

¿Es el Decreto Supremo No. 1.086 una ley en el sentido de la Convención? La respuesta claramente es no. Es más, tampoco se sostiene que el Decreto es una delegación legislativa, por el contrario, es la regulación directa de un derecho humano por el Poder Ejecutivo sin intervención alguna del Poder Legislativo, violando así la CADH. Se debe destacar que el mismo Informe Anual del Instituto Nacional de Derechos Humanos ${ }^{46}$ considera al DS 1.086 reñido con los estándares interamericanos.

\footnotetext{
43 Intervención del representante del Estado Miguel Ángel González en la audiencia pública "Derechos humanos y manifestaciones públicas en Chile", op. cit.

44 Ídem.

45 Corte IDH. La Expresión "Leyes" en el Artículo 30 de la Convención Americana sobre Derechos Humanos. Opinión Consultiva OC-6/86 del 9 de mayo de 1986, párrs. 26 y 35.

46 INDH. Situación de los derechos humanos en Chile. Informe Anual 2011, op. cit., p. 73.
} 


\section{El reproche de la $\mathrm{CIDH}$}

La reacción de la CIDH fue directa y contundente, así el Comisionado para la Niñez, Paulo Sergio Pinheiro, sostuvo: "Creo que la conclusión básica aquí es la siguiente, la manera cómo es que en esas manifestaciones, en las que los niños y adolescentes fueron reprimidos; fue deplorable, lamentable, y hubo claro uso de desproporcionalidad de la fuerza" ${ }^{\prime 4}$.

Por otra parte opinó, con respecto al DS 1.086 y la Justicia Militar que:

[...] es la hora de que el gobierno democrático de Chile piense reformar una ley que es de la dictadura, que es el decreto que regula las manifestaciones [...] Otro punto es sobre la insistencia de esta Comisión, que aquí fue referida, sobre la jurisdicción de los tribunales militares, que es un mantra que esta Comisión repite. Tal vez, el distinguido Gobierno considere que en los gobiernos democráticos, los tribunales militares no consideren delitos civiles involucrados $[\mathrm{sic}]^{48}$.

La Comisionada Luz Patricia Mejía, por otra parte, en su intervención afirmó inequívocamente que la represión fue desmedida y desproporcionada.

\section{Conclusiones: lo que queda para el 2012}

Lo que debe hacer el Estado es casi evidente, y se resume en dos grandes cambios: debe derogar el Decreto Supremo No. 1.086 y regular por ley las manifestaciones públicas, cambiando la Constitución si es necesario. Además debe reformar la jurisdicción militar para que los graves hechos denunciados sean investigados de manera imparcial por los tribunales ordinarios. Sin embargo, también el Estado debería revisar en profundidad la doctrina y preparación de Carabineros de Chile, ya que no es posible la falta de prolijidad observada en el control de manifestaciones públicas, en donde Carabineros pocas veces hizo el ejercicio de diferenciar entre manifestantes pacíficos e infractores.

La finalidad de la audiencia ante la CIDH, no fue manchar el prestigio internacional del Estado, sino que se buscó evidenciar y cuestionar prácticas intolerables, arraigadas y recurrentes durante el año 2011, de las cuales el Estado no se estaba haciendo cargo, y que son reflejo de similares prácticas que se utilizaron en la dictadura militar. Incluso, a principios de 2012, en Aysén, el violento y gravísimo actuar de Carabineros reafirma indudablemente lo sostenido en la audiencia pública.

Lo que nos queda para el 2012, en este tema, es esperar que Chile intervenga fuertemente estas prácticas y la sociedad civil no tenga que recurrir, como último recurso y nuevamente, a algún organismo internacional de protección de derechos humanos.

47 Intervención del comisionado Paulo Sergio Pinheiro en la audiencia pública "Derechos humanos y manifestaciones públicas en Chile", op. cit.

48 Ídem. 